\title{
Angiotensin peptides in the regulation of adrenal cortical function
}

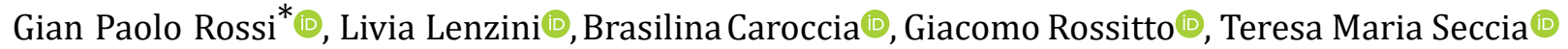 \\ Emergency Medicine Unit and European Society of Hypertension Specialized Center of Excellence for Hypertension, Department \\ of Medicine-DIMED, University of Padua, Italy
}

*Correspondence: Gian Paolo Rossi, FACC, FAHA, DIMED-Hypertension Unit, University Hospital Via Giustiniani 2, 35126 Padova, Italy. gianpaolo.rossi@unipd.it

Academic Editor: Carlos Ferrario, Wake Forest School of Medicine, USA

Received: March 12, 2021 Accepted: May 21, 2021 Published: June 30, 2021

Cite this article: Rossi GP, Lenzini L, Caroccia B, Rossitto G, Seccia TM. Angiotensin peptides in the regulation of adrenal cortical function. Explor Med. 2021;2:294-304. https://doi.org/10.37349/emed.2021.00047

\begin{abstract}
The adrenal cortex plays a key role in the regulation of metabolism, salt and water homeostasis and sex differentiation by synthesizing glucocorticoid, mineralocorticoid and androgen hormones. Evidence exists that angiotensin II regulates adrenocortical function and it has been contended that angiotensin peptides of the non-canonical branch of the renin angiotensin system (RAS) might also modulate steroidogenesis in adrenals. Thus, the aim of this review is to examine the role of the RAS, and particularly of the angiotensin peptides and their receptors, in the regulation of adrenocortical hormones with particular focus on aldosterone production.
\end{abstract}

\section{Keywords}

Angiotensin, peptides, regulations, adrenal, cortical, function

\section{Introduction}

The adrenal cortex plays a key role in the regulation of metabolism, salt and water homeostasis and sex differentiation by synthesizing glucocorticoid, mineralocorticoid and androgen hormones. Hence, an altered regulation in the production of these hormones is involved in the pathophysiology of multiple diseases including high blood pressure, Cushing's and Addison's syndromes, and virilization. A full appreciation of the pathophysiology of these disorders, therefore, requires a deep understanding of the regulation of adrenocortical function.

Excess production of the main mineralocorticoid hormone aldosterone is involved in several human diseases where it plays a substantial role in causing hypertension-mediated organ damage, cardiovascular events, and deaths [1,2]. For example, a secretion of aldosterone in excess of the physiological need is a feature of primary (essential) hypertension associated with overweight and obesity, which involves a multitude of patients affected by the so called "metabolic syndrome" [3]. Secretion of aldosterone occurring in a fashion apparently autonomous from angiotensin (Ang) II and in excess of what needed to preserve body fluids volume and maintain blood pressure, is a key feature of primary aldosteronism, the most common 
curable cause of human arterial hypertension [4]. Furthermore, there are numerous other conditions, as congestive heart failure, liver cirrhosis, nephrotic syndrome, primary reninism, Bartter's and Gitelman's syndromes and renovascular hypertension, which are usually referred to as secondary aldosteronism, where hyperaldosteronism is driven by activation of the renin angiotensin system (RAS) [5]. Therefore, the regulation of aldosterone secretion by angiotensin peptides plays a role that needs to be appreciated in order to fully understand the pathophysiology of hyperaldosteronism. The contention has also been made that angiotensin peptides of the non-canonical branch of the RAS might regulate adrenocortical function and evidence exists that Ang II can also regulate the production of glucocorticoids [6-8].

Thus, this review was conceived to provide information on the regulation of adrenocortical hormones mediated by the RAS and related peptides.

\section{The renin-angiotensin system in the adrenal cortex}

For several years it was contended that a local RAS existed in tissues, including the adrenal cortex. However, conclusive demonstration of this came in the nineties of the last century with the application of molecular biology techniques, as Northern blotting and ribonuclease (RNase) protection assays. This allowed several laboratories to detect renin mRNA in the adrenal cortex of experimental animals and humans $[9,10]$. This suggested the possibility of local generation of Ang I in the adrenal cortex. Further stronger support for this hypothesis was recently provided with use of state-of-the-art techniques, such as digital droplet PCR, which recently allowed to demonstrate the expression also of the angiotensin converting enzyme (ACE)- 1 and the ACE-2 in the human adrenal cortex [11].

ACE-2, a carboxypeptidase which differs from ACE-1, cleaves one amino acid residue from Ang I or Ang II, to form Ang 1-9 and Ang 1-7, respectively. Ang 1-9 can be cleaved to Ang 1-7 by ACE-1 or via the action of alternative endopeptidase, such as neutral endopeptidase or prolyl endopeptidase [12].

The heptapeptide Ang 1-7 has well proven vasodilatory actions, which counteracts Ang II vasoconstriction [13], and exerts cardiovascular protective effects via the $G$ protein-coupled receptor Mas receptor (MasR, reviewed in [14]). In rat cardiac fibroblasts, Ang 1-7 inhibited proliferation and collagen production by reducing extracellular signal-regulated kinase (ERK) 1 and ERK2 kinase activity induced by Ang II [15]. Moreover, in Ang II-infused mice, Ang 1-7 attenuated cardiac hypertrophy, decreased the production of cardiac reactive oxygen species, and increased NO production [16]. Along with results of other studies, these findings suggested that the balance between ACE-1, forming Ang II, and ACE-2, generating Ang 1-7 can be crucial for controlling not only the tissue levels of Ang II, but also the net cardiovascular and modulatory effects of the RAS [17].

Altogether they also suggested the potential for local production of angiotensin peptides, including Ang I, Ang II, and Ang 1-7, in the human adrenal cortex.

Measurements of angiotensin peptides with liquid chromatography tandem-mass spectrometry analysis (LC-MS/MS) in human adrenocortical tissues, comprising aldosterone-producing adenoma (APA), and APAadjacent tissue, and in plasma collected during adrenal vein sampling from the adrenal veins and from the infrarenal inferior vena cava showed that both APA and APA-adjacent tissues have detectable levels of Ang II and Ang III. Furthermore, both Ang II and Ang I showed measurable levels in adrenal vein blood draining both from APA side and from the contralateral normal adrenal gland [11]. However, in spite of the gene expression of ACE-2 in adrenocortical tissues and in plasma draining from the adrenals, Ang 1-7 was by no means detectable. Considering that ACE-2 is the receptor of SARS-CoV2, these findings indicated that the adrenal cortex is a potential target for SARS-CoV2 infection, which can account for cases of adrenal insufficiency in infected patients [18]. Of note, Mao et al. [19] reported the colocalization of ACE2 and transmembrane serine protease 2 (TMPRSS2) in zona fasciculata and zona reticularis of adrenal cortex suggesting that SARS-CoV2 can directly interfere with cortisol secretion and increase the rate of critical illness-related corticosteroid insufficiency in COVID-19 patients.

These novel data, along with the detection of angiotensin receptors in the adrenal cortex, described in the next section, established the basis for a better understanding of the role of the RAS in the adrenal gland. 


\section{Ang II and angiotensin receptors in the regulation of aldosterone production}

Soon after the purification and sequencing of Ang II, the peptide was demonstrated to potently stimulate the secretion of aldosterone [20]. It is now well established that Ang II, by acting through the angiotensin type 1 receptor (AT1R), a member of the seven-transmembrane, G protein-coupled receptor family, stimulates the expression of the aldosterone synthase coding gene (CYP11B2) in a concentration-dependent manner. These results confirmed that Ang II is a potent secretagogue of aldosterone as the increase of CYP11B2 mRNA induced by Ang II is consistently followed by the release of aldosterone in the cell supernatant. What perhaps is less known and investigated is the effect of Ang II on CYP11B1, the cortisol-forming enzyme, as discussed later.

In a systematic search for the different receptor mRNAs, we recently found that all the angiotensin receptors, including the angiotensin type 2 receptor (AT2R), the MasR, and the alamandine receptor (MrgD) are expressed, albeit at a much lower level than the AT1R in the human adrenal cortex (Figure 1). This rank of expression is in agreement with the compelling evidence that the secretagogue effect of Ang II on aldosterone involves activation of AT1R [21].
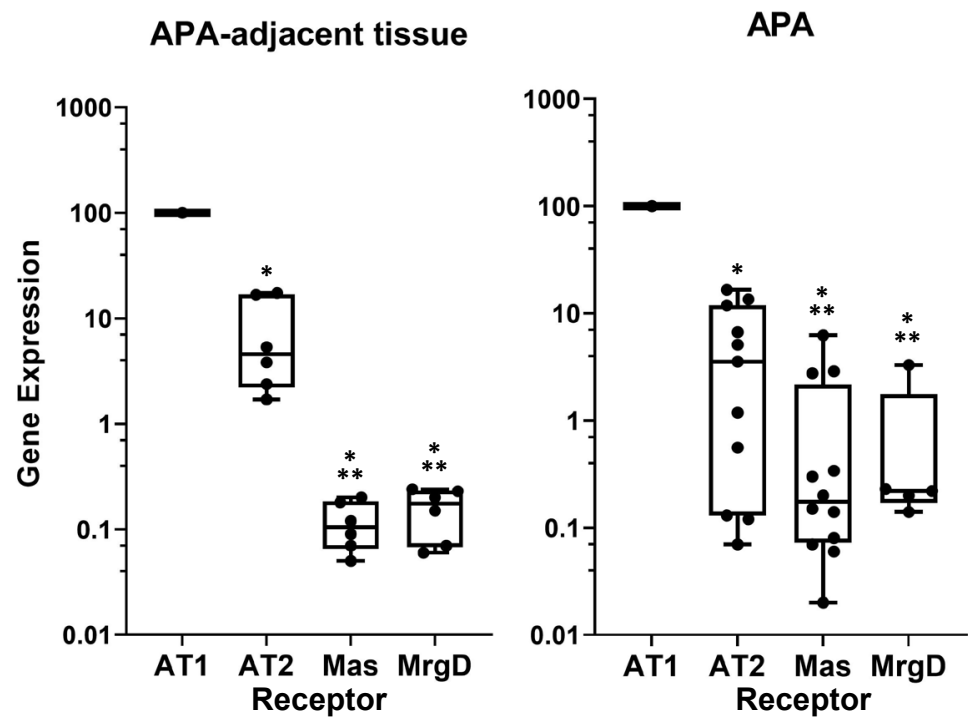

Figure 1. Relative expression of the different angiotensin receptors in human adrenal tissues. Data were obtained by the real-time reverse transcription-polymerase chain reaction (RT-PCR); the different gene expression is calculated with $\Delta \Delta \mathrm{Ct}$ method using porphobilinogen deaminase as housekeeping gene and are presented by setting AT1R expression at $100 \%$ for comparison. * $P<$ 0.0001 vs. AT1R; ** $P<0.01$ vs. AT2R

Ang II stimulates aldosterone production by activating multiple intracellular signaling pathway, the best characterized of which involves an increase of intracellular $\mathrm{Ca}^{2+}$ via activation of the phospholipase C (PLC) and production of diacylglycerol and inositol triphosphate as second messengers (Figure 2). The AT1R-mediated Ang II-stimulated aldosterone production involves a depolarization of the zona glomerulosa cells through modulation of the opening status of two key $\mathrm{K}^{+}$channels: the $\mathrm{G}$ protein-coupled inwardly rectifying potassium channel (GIRK)4, and the Twik-related acid-sensitive $\mathrm{K}^{+}$(TASK) channels (Figure 2). This depolarization opens the voltage-dependent T-type $\mathrm{Ca}^{2+}$ channels.

While the GIRK4 channel functions by transferring $\mathrm{K}^{+}$from inside to outside of zona glomerulosa cells, the TASK channels, a widely distributed family of channels encoded by KCNK genes, generates background, or leak, $\mathrm{K}^{+}$currents. Both channels are essential for maintaining the resting membrane potential of adrenal zona glomerulosa cells at the negative value of $-80 \mathrm{mV}$ [22].

By interrupting these currents, Ang II depolarizes the cell membrane, thus causing opening of the voltage sensitive T-type $\mathrm{Ca}^{2+}$ channels, whose open probability state is proportional to the degree of cell membrane depolarization, and, thereby, inducing activation of aldosterone synthesis (Figure 2) [23]. Mutations in the sequence of the coding gene (KCNJ5) altering GIRK4 channel activity, which lead to excess aldosterone production in both familial and sporadic hyperaldosteronism, results in membrane depolarization and, therefore, in opening of these channels [24]. 


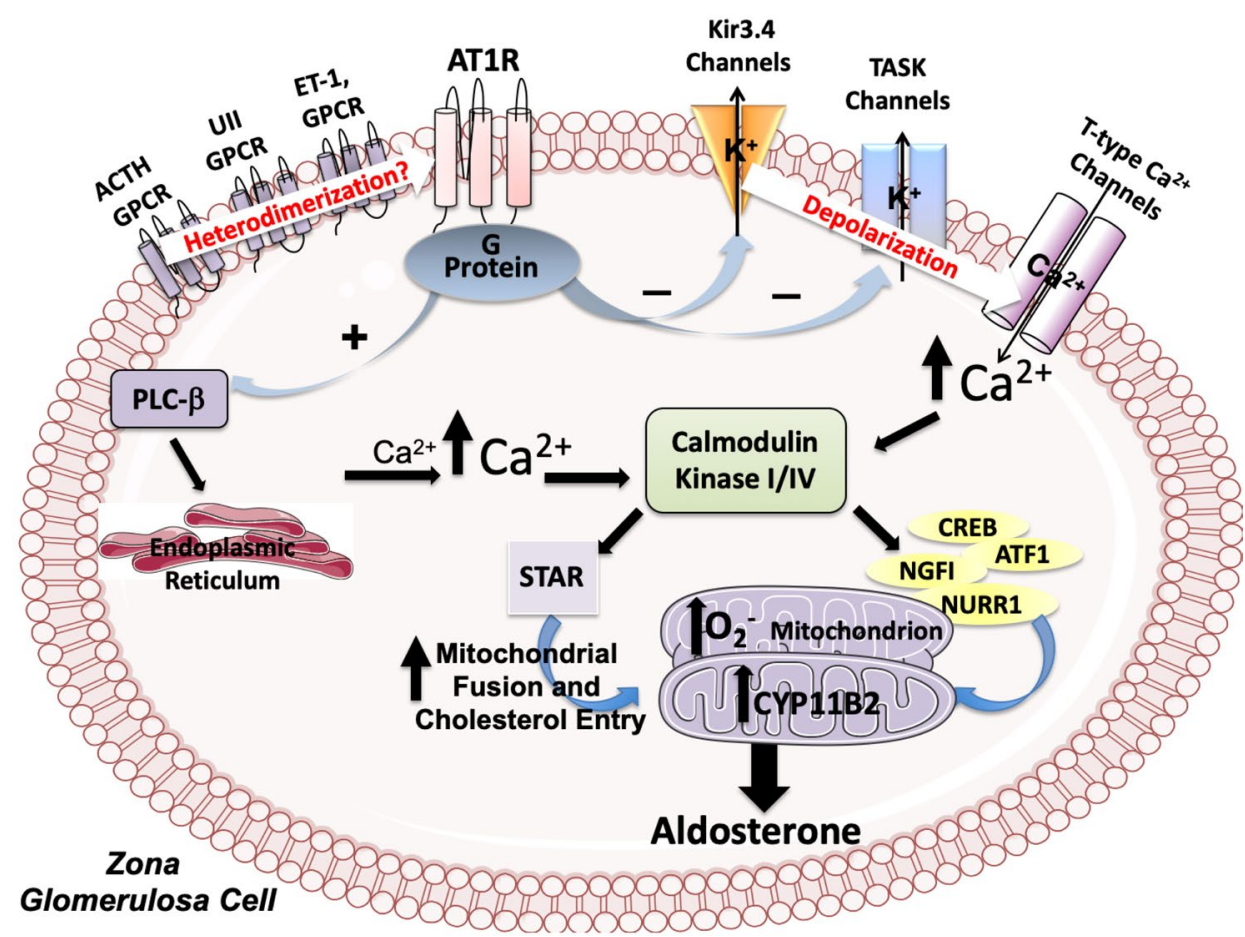

Figure 2. Molecular pathways modulated by Ang II in adrenal zona glomerulosa cells. Ang II, by acting through the AT1R stimulates the expression of the aldosterone synthase coding gene (CYP11B2) by increasing intracellular $\mathrm{Ca}^{2+}$ through the modulation of the activity of the PLC- $\beta$ and of the GIRK4, and of the TASK channels. The increase of intracellular $\mathrm{Ca}^{2+}$ activates the calmodulin kinase (CaMK) cascade which acts on CYP11B2 expression by phosphorylating the transcription factors Activating Transcription Factor 1 (ATF-1), cyclic adenosine monophosphate response element (CRE)-binding protein (CREB) and nuclear receptor related 1 (NURR1). Ang II also increases the aldosterone synthase activity by activating NAPDH oxidase and, thereby, by elevating reactive oxygen species $\left(\mathrm{O}_{2}^{-}\right)$in the mitochondria and by promoting fusion of mitochondria and translocation in these organelles of relevant steroidogenic acute regulatory. Finally, heterodimerization of AT1R with other G protein-coupled receptors (GPCRs) is supposed to be involved in aldosterone synthesis

The increase of intracellular $\mathrm{Ca}^{2+}$ is key for aldosterone synthesis because it activates the CaMK cascade which, through phosphorylation of the STAR protein, increases cholesterol transport in the mitochondria [25]. CaMKI and CaMKIV also act on CYP11B2 expression by phosphorylating the transcription factors ATF-1 and CREB, which bind to CREs and Nerve growth factor-induced clone B (NGFIB), and NURR1 that bind to the Ad-5 and NBRE-1 cis elements [26, 27].

Considering that the AT2R is expressed in the adrenal gland, we explored its role in aldosterone secretion with a pharmacological approach using the AT2R agonist C21 [28] to determine if activation of the AT2R could counter-regulate the AT1R-mediated secretagogue effect of Ang II. These experiments showed that AT2R activation with C21 had no effect on aldosterone production in human adrenocortical cells under unstimulated conditions and also when aldosterone secretion was up-regulated by Ang II [29]. Of note, at high concentration $\left(10^{-5} \mathrm{M}\right) \mathrm{C} 21$ markedly increased CYP11B2 gene expression and enhanced the effect of Ang II on expression of this gene. This effect was abolished by pre-treatment with the AT1R antagonist irbesartan, indicating that at high concentration $\left(10^{-5} \mathrm{M}\right) \mathrm{C} 21$ acts as an AT1R agonist [28].

\section{Effects of Ang II on the mitochondria function}

In steroid-producing cells, cholesterol transport from the outer to the inner mitochondrial membrane is the first and rate-limiting step for the synthesis of all steroid hormones. In fact, several of the enzymes necessary for the biosynthetic pathways are located in mitochondria. Thus, these organelles have been recently pointed out as key in the regulation of aldosterone synthesis mediated by Ang II.

Ang II, by elevating reactive oxygen species in the mitochondria of human and rat adrenocortical cells, provides the oxidative environment that is needed to convert deoxycorticosterone into aldosterone and increased the aldosterone synthase activity by activating nicotinamide adenine dinucleotide phosphate (NAPDH) oxidase [30]. This effect was abolished by either cell treatment with an AT1R antagonist (losartan) and also with an antioxidant (polyethylene glycol-catalase). 
Moreover, it has been showed that Ang II is able to stimulate aldosterone production in adrenal cells also by modulating mitochondria fusion/fission events. Mitochondrial dynamics are implicated not only in maintaining the equilibrium of organelles by repairing or eliminating defective mitochondria [31], but also in regulating steroidogenesis [32].

Accordingly, Ang II was demonstrated to promote aldosterone synthesis in $\mathrm{H} 295$ cells by increasing fusion of mitochondria and translocation in these organelles of relevant steroidogenic proteins, such as STAR, that is responsible for cholesterol transport from the outer to the inner mitochondrial membrane, and protein kinase $\mathrm{C}(\mathrm{PKC}) \varepsilon$, mitogen-activated protein kinase (MEK) and ERK, that drive the activation signaling in mitochondria [33]. Whether and how this occurs in APA, where, as mentioned above, Ang II is low, remains to be investigated [11].

\section{Angiotensin peptides and cortisol and androgen biosynthesis}

Adrenal zona fasciculata secretes glucocorticoids mainly in response to adrenocorticotropic hormone (ACTH), but not only. It also responds to Ang II [34-36] in line with the notion that the AT1R is expressed in this zona in different species [6-8, 37].

As proof-of-concept that Ang II can regulate cortisol production, we provided in vivo evidences for a stimulatory effect of Ang II by treating rats with Ang II $(700 \mu \mathrm{g} / \mathrm{kg} \cdot$ day $)$ for 1 -week and demonstrating an increase of immunodetectable 11- $\beta$ hydroxylase in the adrenal cortex (Figure 3) [38]. Furthermore, by acting on AT1R, Ang II, significantly increased CYP11B1 gene expression in adrenocortical cell line H295R and its sub-clone HAC15, and also in strips obtained from APA-adjacent tissue and APA [11,28].

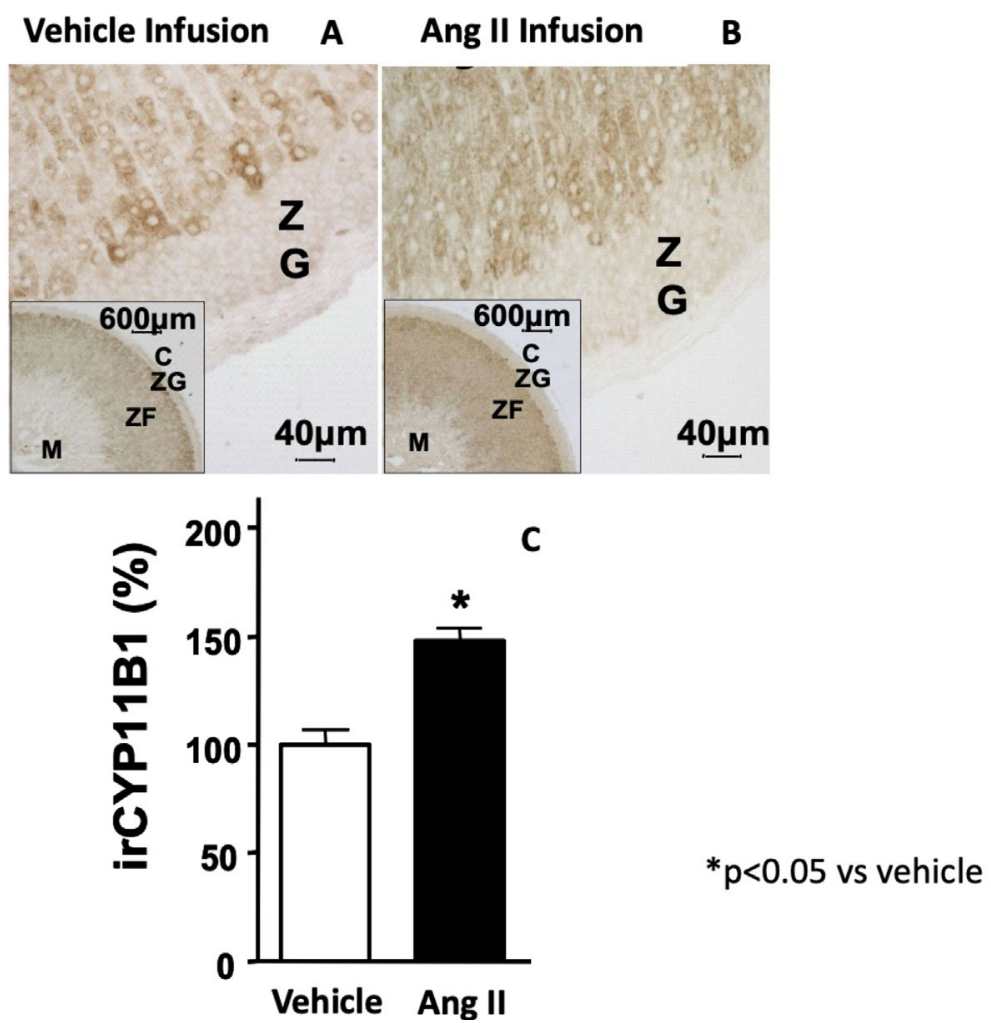

Figure 3. 11- $\beta$ hydroxylase immunostaining of rat adrenal cortex after the treatment with vehicle (Panel A) and Ang II (700 $\mu \mathrm{g} /$ $\mathrm{kg}$-day) for 1 -week (Panel B). Quantitative analysis of immunostaining showed a significant increase of the 11- $\beta$ hydroxylase protein expression after Ang II treatment as compared to vehicle (Panel C)

Note. Adapted with permission from "Expression and functional role of urotensin-Il and its receptor in the adrenal cortex and medulla: novel insights for the pathophysiology of primary aldosteronism.” Giuliani L, Lenzini L, Antonello M, Aldighieri E, Belloni AS, Fassina A, et al. J Clin Endocrinol Metab. 2009;94:684-90. (https://doi.org/10.1210/jc.2008-1131). () Oxford University Press

Like in zona glomerulosa cells, a pivotal role for cortisol synthesis is played by depolarization-dependent $\mathrm{Ca}^{2+}$ entry; moreover, both T-type and L-type $\mathrm{Ca}^{2+}$ channels were identified as mediators of Ang II-stimulated cortisol secretion in bovine and human zona fasciculata cells $[39,40]$. Noteworthy, Ang II receptor activation 
is coupled to membrane depolarization through inhibition of the potassium two pore domain channel subfamily K member TWIK-related potassium channel (TREK)-1 [41].

To date, notwithstanding the AT1R expression in the androgen-producing adrenocortical zona reticularis [42], information on whether Ang II affects the biosynthesis and secretion of androgen is lacking.

\section{Role of angiotensin peptides other than Ang II}

Ang III has been found to increase aldosterone secretion from rabbit and rat adrenal gland [43, 44]. This effect was partially blunted by the AT2R antagonist PD123319 and was affected by the AT1R antagonist candesartan[45]. A secretagogue effect of Ang III on aldosterone has been also reported in human HAC15 cells, but, at variance with what found in rat adrenocortical zona glomerulosa, in humans Ang III-stimulated aldosterone production was abolished by losartan, suggesting an AT1R-mediated regulation [46]. Of note, Ang II was far more potent than Ang III in stimulating aldosterone secretion in all models investigated thus far.

As human adrenocortical tissues express not only the AT1R but also, albeit at much lower levels, the AT2R and the MasR, we recently investigated the effects of Ang 1-7 on aldosterone and cortisol production in H295R cells. We found that at concentrations ranging from $10^{-8}$ to $10^{-7} \mathrm{M}$, Ang 1-7 elicited no effects on CYP11B1 or CYP11B2 gene expression [11]. We observed a significant increase in CYP11B1 and CYP11B2 mRNA at concentrations ranging from $10^{-6}$ to $10^{-4} \mathrm{M}$. This effect was blunted by the MasR antagonist A779, and abolished by the AT1R antagonist irbesartan, suggesting that at high concentration Ang 1-7 stimulates CYP11B2 and CYP11B1 via activation of the AT1R.

Of note, when added on top of Ang II, Ang 1-7 did not blunt Ang II induced expression of CYP11B2 and CYP11B1 mRNA [11]. Opposite to our results, Itcho et al. [47] reported a weak blunting effect of $10^{-8} \mathrm{~mol} / \mathrm{L}$ Ang 1-7 on aldosterone secretion and CYP11B2 gene expression induced by $10^{-8} \mathrm{~mol} / \mathrm{L}$ Ang II in HAC15 cells. However, those authors did not use purified or and/or synthetic Ang 1-7 but conditioned medium obtain after 6 hours incubation of HAC15 with Ang II. Moreover, they could only presume that their cells would have generated Ang 1-7 as neither they measured Ang 1-7 concentration in the medium nor did they rule the presence of other aldosterone release modulators [47]. However, it was also reported that at $10^{-6} \mathrm{~mol} / \mathrm{L}$ Ang 1-7 blunted Ang II- and ACTH-induced aldosterone production by acting through MasR in rat zona glomerulosa cells [48]. As this is a high concentration of Ang 1-7 and the relative quantity of the AT1R, AT2R, and MasR was not determined in rat zona glomerulosa [48], a possible off target effect of Ang 1-7 cannot be ruled out. Moreover, these divergent results could be explained by species differences, given that for example Ang II receptors do not play the same role in rodents and humans.

\section{Interactions of angiotensin receptor with other receptors involved in aldosterone synthesis}

Even though on the whole, the available evidences indicate that Ang II is the main secretagogue of aldosterone, research in the last decades showed that at least a dozen of other factors regulates the biosynthesis and secretion of aldosterone in the adrenal zona glomerulosa and interact in a complex way. For example, endothelin (ET)-1 was in vitro shown to be equipotent to Ang II in stimulating aldosterone secretion in human adrenocortical cells and in strip preparations acting via both $\mathrm{ET}_{\mathrm{A}}$ and $\mathrm{ET}_{\mathrm{B}}$ receptors [49-51]. Moreover, the incubation of zona glomerulosa cells with Ang II on top of ET-1 resulted in a significant potentiation of Ang II effect on aldosterone secretion suggesting a cross-talk between ET-1 and Ang II [52]. Of note, Ang II by acting via AT1R stimulates ET-1 release and expression [53, 54] and in turn, ET-1 increases Ang II formation [55].

Besides their secretagogue action on the secretory activity of the adrenal gland, Ang II and ET-1 promote hypertrophy and hyperplasia of the zona glomerulosa $[56,57]$ via AT1R [56]- and $\mathrm{ET}_{\mathrm{A}}$ - $[51,58]$ dependent mechanisms, respectively. Both peptides exert their mitogenic effects through PKC dependent activation of the p42/p44 mitogen-activated protein (MAP)-kinase cascade [58, 59]. The expression of a chymase-mediated biosynthetic pathway alternative to the endothelin converting enzyme-1 in the human adrenal cortex capable of generating ET-1-31 also suggested that conversion of pro-endothelin 1 to ET-1-31, a predominant endothelin A receptor agonist, or to ET-1, a mixed endothelin A and B agonist, could direct adrenocortical 
stem cells in the cambium layer toward differentiation into a proliferogenic/hypertrophic phenotype or a secretory phenotype [51]. Hence, the cross-talk between Ang II stimulating formation of ET-1 and chymase generating ET-1-31 could be relevant for controlling the differentiation of zona glomerulosa cells according to the physiological needs.

Information on the interactions between Ang II and other factors are much more scant, although studies have raised the possibility that association as heteromeric complexes of AT1R with other receptors may be one of the mechanisms by which AT1R can diversify and modulate its signaling [60]. A heteromerization between the AT1R and other GPCRs had been demonstrated in several tissues and cell types, but not in the adrenal cortex, until we could show this phenomenon to occur in vitro in HAC15 cells [61]. In these human adrenocortical carcinoma cells, heterodimerization of AT1R with the G protein-coupled estrogen receptor (GPER) potentiated the GPER-mediated effect on CYP11B2 expression. Thus, it is conceivable that heterodimerization of Ang II receptors, particularly of AT1R, with other GPCRs known to stimulate aldosterone, such as the endothelin receptors [50], adrenocorticotropic hormone receptor [21] and urotensin II receptor [38], can represent a putative additional mechanism capable of finely tuning aldosterone synthesis in the adrenal cortex both in physiological and disease conditions.

\section{Conclusions}

In summary, compelling evidences have confirmed the role of Ang II as an important secretagogue for aldosterone and also for cortisol. Moreover, accumulating data have shown that the regulation of adrenocortical hormone biosynthesis is a far more complex process involving a number of additional factors, among which ET-1 and other peptides may act through different receptors and complex interactions of their receptors. Improved technology will undoubtedly provide a better understanding of these complex processes and, therefore, should be a goal of future research resources.

\section{Abbreviations}

ACE: angiotensin converting enzyme

Ang: angiotensin

APA: aldosterone-producing adenoma

AT1R: angiotensin type 1 receptor

AT2R: angiotensin type 2 receptor

CaMK: calmodulin kinase

ERK: extracellular signal-regulated kinase

ET: endothelin

GIRK: G protein-coupled inwardly rectifying potassium channel

GPCRs: G protein-coupled receptors

MasR: Mas receptor

RAS: renin angiotensin system

STAR: steroidogenic acute regulatory

TASK: Twik-related acid-sensitive $\mathrm{K}^{+}$

\section{Declarations}

\section{Author contributions}

GPR conceived and revised the manuscript; LL and BC wrote the manuscript; GR and TMS revised the manuscript.

\section{Conflicts of interest}

Not applicable. 


\section{Ethical approval}

Not applicable.

\section{Consent to participate}

Not applicable.

\section{Consent to publication}

Not applicable.

Availability of data and materials

Not applicable.

\section{Funding}

Not applicable.

\section{Copyright}

(c) The Author(s) 2021.

\section{References}

1. Catena C, Colussi G, Nadalini E, Chiuch A, Baroselli S, Lapenna R, et al. Cardiovascular outcomes in patients with primary aldosteronism after treatment. Arch Intern Med. 2008;168:80-5.

2. Rossi GP, Sechi LA, Giacchetti G, Ronconi V, Strazzullo P, Funder JW. Primary aldosteronism: cardiovascular, renal and metabolic implications. Trends Endocrinol Metab. 2008;19:88-90.

3. Rossi GP, Belfiore A, Bernini G, Fabris B, Caridi G, Ferri C, et al. Body mass index predicts plasma aldosterone concentrations in overweight-obese primary hypertensive patients. J Clin Endocrinol Metab. 2008;93:2566-71.

4. Rossi GP. Primary Aldosteronism: JACC State-of-the-Art Review. J Am Coll Cardiol. 2019;74:2799-811.

5. Schrier RW, Gurevich AK, Cadnapaphornchai MA. Pathogenesis and management of sodium and water retention in cardiac failure and cirrhosis. Semin Nephrol. 2001;21.157-72

6. Bird IM, Williams BC, Walker SW. Identification and metabolism of phosphoinositol species formed on angiotensin II stimulation of zona fasciculata-reticularis cells from the bovine adrenal cortex. Mol Cell Endocrinol. 1992;83:29-38.

7. Burnay MM, Vallotton MB, Capponi AM, Rossier MF. Angiotensin II potentiates adrenocorticotrophic hormone-induced cAMP formation in bovine adrenal glomerulosa cells through a capacitative calcium influx. Biochem J. 1998;330:21-7.

8. Naville D, Lebrethon MC, Kermabon AY, Rouer E, Benarous R, Saez JM. Characterization and regulation of the angiotensin II type-1 receptor (binding and mRNA) in human adrenal fasciculata-reticularis cells. FEBS Lett. 1993;321:184-8.

9. Naruse M, Sussman CR, Naruse K, Jackson R V., Inagami T. Renin exists in human adrenal tissue. J Clin Endocrinol Metab. 1983;57:482-7.

10. Sarzani R, Fallo F, Dessì-Fulgheri P, Pistorello M, Lanari A, Paci VM, et al. Local renin-angiotensin system in human adrenals and aldosteronomas. Hypertension. 1992;19:702-7.

11. Caroccia B, Vanderriele P, Seccia TM, Piazza M, Lenzini L, Prisco S, et al. Aldosterone and cortisol synthesis regulation by angiotensin-(1-7) and angiotensin-converting enzyme 2 in the human adrenal cortex. J Hypertens. 2021; [Epub ahead of print].

12. Arendse LB, Danser AH, Poglitsch M, Touyz RM, Burnett JC, Llorens-Cortes C, et al. Novel therapeutic approaches targeting the renin-angiotensin system and associated peptides in hypertension and heart failure. Pharmacol Rev. 2019;71:539-70. 
13. Santos RA, Simoes e Silva AC, Maric C, Silva DMR, Machado RP, de Buhr I, et al. Angiotensin-(1-7) is an endogenous ligand for the G protein-coupled receptor Mas. Proc Natl Acad Sci U S A. 2003;100:8258-63.

14. Santos RAS, Sampaio WO, Alzamora AC, Motta-Santos D, Alenina N, Bader M, et al. The ACE2/ Angiotensin-(1-7)/Mas axis of the renin-angiotensin system: focus on Angiotensin-(1-7). Physiol Rev. 2018;98:505-53.

15. McCollum LT, Gallagher PE, Tallant EA. Angiotensin-(1-7) abrogates mitogen-stimulated proliferation of cardiac fibroblasts. Peptides. 2012;34:380-8.

16. Zhong J, Basu R, Guo D, Chow FL, Byrns S, Schuster M, et al. Angiotensin-converting enzyme 2 suppresses pathological hypertrophy, myocardial fibrosis, and cardiac dysfunction. Circulation. 2010;122:717-28.

17. Ferrario CM, Chappell MC. Novel angiotensin peptides. Cell Mol Life Sci. 2004;61.2720-7.

18. Chen N, Zhou M, Dong X, Qu J, Gong F, Han Y, et al. Epidemiological and clinical characteristics of 99 cases of 2019 novel coronavirus pneumonia in Wuhan, China: a descriptive study. Lancet. 2020;395:507-13.

19. Mao Y, Xu B, Guan W, Xu D, Li F, Ren R, et al. The adrenal cortex, an underestimated site of SARS-CoV-2 infection. Front Endocrinol (Lausanne). 2021;11:593179.

20. Mulrow PJ, Ganong WF. Stimulation of aldosterone secretion by angiotensisn. II. A preliminary report. Yale J Biol Med. 1961;33:386-95.

21. Spät A, Hunyady L. Control of aldosterone secretion: a model for convergence in cellular signaling pathways. Physiol Rev. 2004;84:489-539.

22. Bayliss DA, Barrett $P Q$. Emerging roles for two-pore-domain potassium channels and their potential therapeutic impact. Trends Pharmacol Sci. 2008;29:566-75.

23. Oki K, Plonczynski MW, Lam ML, Gomez-Sanchez EP, Gomez-Sanchez CE. The potassium channel, Kir3.4 participates in angiotensin II-stimulated aldosterone production by a human adrenocortical cell line. Endocrinology. 2012;153:4328-35.

24. Lenzini L, Prisco S, Caroccia B, Rossi GP. Saga of Familial Hyperaldosteronism: yet a new channel. Hypertension. 2018;71:1010-4.

25. Pezzi V, Clark BJ, Ando S, Stocco DM, Rainey WE. Role of calmodulin-dependent protein kinase II in the acute stimulation of aldosterone production. J Steroid Biochem Mol Biol. 1996;58:417-24.

26. Pezzi V, Clyne CD, Ando S, Mathis JM, Rainey WE. Ca ${ }^{2+}$-regulated expression of aldosterone synthase is mediated by calmodulin and calmodulin-dependent protein kinases. Endocrinology. 1997;138:835-8.

27. Bassett MH, White PC, Rainey WE. The regulation of aldosterone synthase expression. Mol Cell Endocrinol. 2004;217:67-74.

28. Vanderriele PE, Caroccia B, Seccia TM, Piazza M, Lenzini L, Torresan F, et al. The angiotensin type 2 receptor in the human adrenocortical zona glomerulosa and in aldosterone-producing adenoma: low expression and no functional role. Clin Sci (Lond). 2018;132:627-40.

29. Ogishima T, Mitani F, Ishimura Y. Isolation of aldosterone synthase cytochrome P-450 from zona glomerulosa mitochondria of rat adrenal cortex. J Biol Chem. 1989;264:10935-8.

30. Rajamohan SB, Raghuraman G, Prabhakar NR, Kumar GK. NADPH oxidase-derived $\mathrm{H}_{2} \mathrm{O}_{2}$ contributes to angiotensin II-induced aldosterone synthesis in human and rat adrenal cortical cells. Antioxid Redox Signal. 2012;17:445-59.

31. Martin SJ. Mitochondrial fusion: Bax to the fussure. Dev Cell. 2011;20:142-3.

32. Duarte A, Poderoso C, Cooke M, Soria G, Cornejo Maciel F, Gottifredi V, et al. Mitochondrial fusion is essential for steroid biosynthesis. PLoS One. 2012;7:e45829.

33. Helfenberger KE, Castillo AF, Mele PG, Fiore A, Herrera L, Finocchietto P, et al. Angiotensin II stimulation promotes mitochondrial fusion as a novel mechanism involved in protein kinase compartmentalization and cholesterol transport in human adrenocortical cells. J Steroid Biochem Mol Biol. 2019;192:105413. 
34. Mlinar B, Biagi BA, Enyeart JJ. Losartan-sensitive AII receptors linked to depolarization-dependent cortisol secretion through a novel signaling pathway. J Biol Chem. 1995;270:20942-51.

35. Lebrethon MC, Jaillard C, Defayes G, Begeot M, Saez JM. Human cultured adrenal fasciculata-reticularis cells are targets for angiotensin-II: effects on cytochrome P450 cholesterol side-chain cleavage, cytochrome P450 17 alpha-hydroxylase, and 3 beta-hydroxysteroid-dehydrogenase messenger ribonucleic acid and proteins and on steroidogenic responsiveness to corticotropin and angiotensin-II. J Clin Endocrinol Metab. 1994;78:1212-9.

36. Clyne CD, Nicol MR, Macdonald ST, Williams BC, Walker SW. Angiotensin II stimulates growth and steroidogenesis in zona fasciculata/reticularis cells from bovine adrenal cortex via the AT1 receptor subtype. Endocrinology. 1993;132:2206-12.

37. Braley LM, Menachery AI, Brown EM, Williams GH. Comparative effect of angiotensin II, potassium, adrenocorticotropin, and cyclic adenosine $3^{\prime}, 5^{\prime}$-monophosphate on cytosolic calcium in rat adrenal cells. Endocrinology. 1986;119:1010-9.

38. Giuliani L, Lenzini L, Antonello M, Aldighieri E, Belloni AS, Fassina A, et al. Expression and functional role of urotensin-II and its receptor in the adrenal cortex and medulla: novel insights for the pathophysiology of primary aldosteronism. J Clin Endocrinol Metab. 2009;94:684-90.

39. Enyeart JJ, Enyeart JA. Adrenal fasciculata cells express T-type and rapidly and slowly activating L-type $\mathrm{Ca}^{2+}$ channels that regulate cortisol secretion. Am J Physiol Cell Physiol. 2015;308:C899-918.

40. Greenberg RK, Lu Q, Roselli EE, Svensson LG, Moon MC, Hernandez AV, et al. Contemporary analysis of descending thoracic and thoracoabdominal aneurysm repair: a comparison of endovascular and open techniques. Circulation. 2008;118:808-17.

41. Albuquerque FC Jr, Tonnessen BH, Noll RE Jr, Cires G, Kim JK, Sternbergh WC 3rd. Paradigm shifts in the treatment of abdominal aortic aneurysm: trends in 721 patients between 1996 and 2008. J Vasc Surg. 2010;51:1348-52.

42. Spät A, Hunyady L, Szanda G. Signaling interactions in the adrenal cortex. Front Endocrinol (Lausanne). 2016;7:17.

43. Chiu AT, Peach MJ. Inhibition of induced aldosterone biosynthesis with a specific antagonist of angiotensin II. Proc Natl Acad Sci U S A. 1974;71:341-4.

44. Goodfriend TL, Peach MJ. Angiotensin III: (des-aspartic acid 1 )-angiotensin II. Evidence and speculation for its role as an important agonist in the renin-angiotensin system. Circ Res. 1975;36:38-48.

45. Yatabe J, Yoneda M, Yatabe MS, Watanabe T, Felder RA, Jose PA, et al. Angiotensin III stimulates aldosterone secretion from adrenal gland partially via angiotensin II type 2 receptor but not angiotensin II type 1 receptor. Endocrinology. 2011;152:1582-8.

46. Oki K, Kopf PG, Campbell WB, Lam ML, Yamazaki T, Gomez-Sanchez CE, et al. Angiotensin II and III metabolism and effects on steroid production in the HAC15 human adrenocortical cell line. Endocrinology. 2013;154:214-21.

47. Itcho K, Oki K, Kobuke K, Ohno H, Yoneda M, Hattori N. Angiotensin 1-7 suppresses angiotensin II mediated aldosterone production via JAK/STAT signaling inhibition. J Steroid Biochem Mol Biol. 2019;185:137-41.

48. Shefer G, Marcus Y, Knoll E, Dolkart O, Foichtwanger S, Nevo N, et al. Angiotensin 1-7 is a negative modulator of aldosterone secretion in vitro and in vivo. Hypertension. 2016;68:378-84.

49. Rossi GP, Albertin G, Neri G, Andreis PG, Hofmann S, Pessina AC, et al. Endothelin-1 stimulates steroid secretion of human adrenocortical cells ex vivo via both ETA and ETB receptor subtypes. J Clin Endocrinol Metab. 1997;82:3445-9.

50. Rossi G, Albertin G, Belloni A, Zanin L, Biasolo MA, Prayer-Galetti T, et al. Gene expression, localization, and characterization of endothelin A and B receptors in the human adrenal cortex. J Clin Invest. 1994;94:1226-34. 
51. Rossi GP, Andreis PG, Colonna S, Albertin G, Aragona F, Belloni AS, et al. Endothelin-1[1-31]: a novel autocrine-paracrine regulator of human adrenal cortex secretion and growth. J Clin Endocrinol Metab. 2002;87:322-8.

52. Cozza EN, Chiou S, Gomez-Sanchez CE. Endothelin-1 potentiation of angiotensin II stimulation of aldosterone production. Am J Physiol. 1992;262:R85-9.

53. Hong HJ, Chan P, Liu JC, Juan SH, Huang MT, Lin JG, et al. Angiotensin II induces endothelin-1 gene expression via extracellular signal-regulated kinase pathway in rat aortic smooth muscle cells. Cardiovasc Res. 2004;61:159-68.

54. Emori T, Hirata Y, Ohta K, Kanno K, Eguchi S, Imai T, et al. Cellular mechanism of endothelin-1 release by angiotensin and vasopressin. Hypertension. 1991;18:165-70.

55. Kawaguchi H, Sawa H, Yasuda H. Endothelin stimulates angiotensin I to angiotensin II conversion in cultured pulmonary artery endothelial cells. J Mol Cell Cardiol. 1990;22:839-42.

56. McEwan PE, Vinson GP, Kenyon CJ. Control of adrenal cell proliferation by AT1 receptors in response to angiotensin II and low-sodium diet. Am J Physiol. 1999;276:E303-9.

57. Mazzocchi G. Endothelins stimulate deoxyribonucleic acid synthesis and cell proliferation in rat adrenal zona glomerulosa, acting through an endothelin A receptor coupled with protein kinase $\mathrm{C}$ - and tyrosine kinase-dependent signaling pathways. Endocrinology. 1997;138:2333-7.

58. Mazzocchi G, Rossi GP, Malendowicz LK, Champion HC, Nussdorfer GG. Endothelin-1[1-31], acting as an ETA-receptor selective agonist, stimulates proliferation of cultured rat zona glomerulosa cells. FEBS Lett. 2000;487:194-8.

59. McNeill H, Whitworth E, Vinson GP, Hinson JP. Distribution of extracellular signal-regulated protein kinases 1 and 2 in the rat adrenal and their activation by angiotensin II. J Endocrinol. 2005;187:149-57.

60. Rukavina Mikusic NL, Silva MG, Pineda AM, Gironacci MM. Angiotensin receptors heterodimerization and trafficking: how much do they influence their biological function? Front Pharmacol. 2020;11:1179.

61. Caroccia B, Seccia TM, Campos AG, Gioco F, Kuppusamy M, Ceolotto G, et al. GPER-1 and estrogen receptor- $\beta$ ligands modulate aldosterone synthesis. Endocrinology. 2014;155:4296-304. 